\title{
PROGRESS IN BACTERIAL ENDOCARDITIS
}

\author{
By J. E. Cates, M.D., M.R.C.P. \\ Lecturer in Medicine, I'niversity of Bristol; Assistant Physician, United Bristol Hospitals
}

\section{Introduction}

The success of penicillin in bacterial endocarditis has created new problems for the clinician. These include the need to make an early diagnosis, the choice of antibiotic, the difficulty of telling whether infection has been eliminated, and the prognosis when infection has been controlled. Moreover, the proper use of antibiotics to prevent bacterial endocarditis is of great importance. When each new antibiotic is introduced the question of its use in endocarditis has to be settled. However, it is becoming clear that penicillin still has pride of place, and that only in rare cases are other antibiotics of any value in this disease.

\section{Definitions}

The older classification of 'acute' and 'subacute' depended on whether the patient survived six or eight weeks or not, and this was largely determined by the virulence of the infecting organism. Though virulence no longer decides the prognosis, there are differences in aetiology and modes of onset between the acute and subacute forms so that these terms still serve a purpose. However, it has now become more important to define each case by its infecting organism, for upon that the treatment and prognosis largely depend.

\section{Changes in Incidence}

In England and Wales, before the days of penicillin, about a thousand deaths were certified each year as being due to acute or subacute bacterial endocarditis. Now that the disease can often be cured the incidence cannot be judged by the Registrar General's figures, and it is necessary to depend on small groups, personal experience, and conjecture.

Many cardiologists would admit that they see fewer subacute cases than previously, but this may mean that these patients are being treated in local hospitals.
While the number of cases seen in the larger hospitals is declining there is no doubt that the proportion due to penicillin-resistant organisms has increased. Presumably this is partly due to prevention of many penicillin-sensitive infections by proper prophylaxis.

Acute bacterial endocarditis has always been less common than the subacute form, and is becoming even rarer. This change may be due to the prompt use and rapid effect of chemotherapy in severe infections. For instance, uterine sepsis was once a common cause of $\beta$-haemolytic streptococcal endocarditis; in one puerperal sepsis unit in which the yearly average used to be six cases, from 1946 to $195^{\circ}$ there were no cases at all (Ramsay, 1950).

The commonest form of acute bacterial endocarditis now seems to be staphylococcal (Anderson and Keefer, I948; Levinson, Griffith and Pear son, 1950), and these infections are often due to penicillin-resistant strains.

\section{Aetiology}

When the Penicillin Trials Committee of the Medical Research Council organized clinical trials in subacute bacterial endocarditis it was agreed to collect data concerning the aetiology of the disease. In this way the study of 442 patients served to extend our knowledge of the underlying heart disease and of the possible sources of infection (Cates and Christie, 195I).

\section{Underlying Lesions}

It is well known that in subacute bacterial endocarditis there is nearly always some underlying heart disease, and in the M.R.C. series this was due to acquired heart disease in 87 per cent. and to congenital in 13 per cent.-in under $x$ per cent. both forms were present. There seems little doubt, however, that subacute bacterial endocarditis may begin in a normal heart; in as many as 6 per cent. of American cases (Anderson and Keefer, 1948) this was thought to have been the 
case, but these figures may be fallacious because those cases in which there is at first no clinical evidence of heart disease may prove to be infections either of bicuspid aortic valves or of MacCallum's patch. In one curious group, the subacute bacterial endocarditis of addicts who give themselves intravenous opium, it is the rule rather than the exception for infection to begin in apparently normal hearts (Luttgens, 1949).

\section{Acquired Heart Lesions}

In the M.R.C. series the acquired lesions were probably rheumatic in at least 90 per cent. (although this was recognized in life in only 76 per cent.). Occasional predisposing lesions are arteriosclerosis, syphilis and perhaps coronary thrombosis.

In acquired lesions it is most common to find signs of mitral valve disease alone ( 47 per cent.). It is uncommon for there to be aortic valve disease alone ( 13 per cent.), whereas signs that both aortic and mitral valves were diseased were found in 40 per cent. of the M.R.C. cases.

Infection of the mitral valve alone is almost twice as common in females as in males; infection of the aortic valve alone is five times more common in males than in females; when there are signs of both mitral and aortic disease the two sexes are equally affected. Infection may spread to the tricuspid and pulmonary valves, but these complications are rarely diagnosed during life.

As McDonald (1946) has shown, the presence of auricular fibrillation does not preclude the existence of bacterial endocarditis; however, the great majority of patients have normal cardiac rhythm, and in only 2 per cent. of the M.R.C. series was fibrillation present before treatment.

It appears that acute rheumatism may play a greater part in bacterial endocarditis than is generally recognized. Thus, histological studies suggest that implantation of bacteria on heart valves may coincide with an attack or relapse of acute rheumatism (MacIlwaine, 1947). There is also some evidence that acute rheumatism may contribute to the development of heart failure during treatment (Matthew and Gilchrist, 1948-49).

There have been further reports of a rare but interesting form of bacterial infection that occurs in traumatic arteriovenous aneurysms (Stojanovic and Slavkovic, 1948; Cutler and Wolf, 1946). There is often infection of the aortic valves as well as of the aneurysmal sac, and it has been suggested that damage to these valves follows the increased heart output and paves the way to their infection (Cutler and Wolf, loc. cit.). There have also been reports of infection after Blalock's operation (Hurst, Gleason and Schemm, 1949;
Harvey, Mirick and Schaub, 1949), but it is not clear whether infection began at the site of the surgical anastomosis or on the congenital defecop.

\section{Congenital Lesions}

Of congenital lesions found to underlie subacute bacterial endocarditis, ventricular septal defect the commonest. Next comes patent ductu arteriosus; this abnormality and infection of it a a more common in females. Occasionally infection develops in pulmonary stenosis, Fallot's tetralog coarctation of the aorta and, very rarely, in atrig septal defects.

Bicuspid aortic valves cannot be diagnosect during life, and even at post-mortem it is difficus? to say whether a bicuspid deformity is congenit or the result of rheumatic infection (Lewis and Grant, 1923). On this point post-mortem findingo in the M.R.C. series are of interest; there were cases with aortic disease alone and in five ( 40 pe् cent.) these valves were bicuspid; but there were 45 with both aortic and mitral valve disease and in only two ( 5 per cent.) were the aortic valves bicuspid.

\section{Underlying Lesion in Acute Bacterial Endocardit.}

In acute bacterial endocarditis it is well esgalos lished that there is often no evidence of existing heart disease. The figures vary in the different infections; in three series of pneu coccal endocarditis there was pre-existing diseas in one-third (Tinsley, 1945), one-quarter (Luxtow and Smith, I943) and one-fifth of cases (Anderso and Keefer, 1948). In staphylococcal infection Thayer's figures were 43 per cent. (Thayer I93 I while more recent American figures were 31 per cent. of I 8 cases (Anderson and Keefer, I948 The same authorities reported 44 per cent. for acute infections due to haemolytic streptococcs. In a small series of meningococcal endocarditas (Firestone, 1946) the figure of pre-existing diseașe is under 20 per cent., which is similar to gone coccal endocarditis (Thayer, I93I).

\section{Possible Sources of Infection}

It is well known that dental sepsis and extractiog of teeth cause a bacteraemia with Streptococc viridans and that both may precede the develop? ment of subacute bacterial endocarditis. In thes country and in the U.S.A. about ro per cent. patients have a history of recent extractions arel another third are found to have dental sepsis. Other foci of infection may be found in the noæ and throat and elsewhere, but in about 40 per cenfe. of cases no primary infection is found. It has been suggested that dental extractions are wrong blamed for causing endocarditis (Feldman and Trace, 1938 ), but even so, dental sepsis is probab 
culpable more often than the above figures suggest. A large apical abscess can be silent in bacterial endocarditis, and it is easy to forget to $\mathrm{X}$-ray the mouth of a patient who has just recovered from this ominous illness. In two of the M.R.C. patients it was shown that a full course of penicillin, enough to arrest bacterial endocarditis, may fail to kill penicillin-sensitive organisms buried in the depths of an apical abscess. This disquieting finding suggests that such foci, unless removed, are potential causes of re-infection of the heart valves. Therefore, it is essential to make a deliberate search for dental sepsis before patients leave hospital.

In endocarditis due to enterococci (Streptococcus faecalis) a focus of infection or a portal of entry for organisms is usually found in sites other than the mouth. The main dangers are urinary infections and prostatectomy in elderly men, and uterine infections in women (Robbins and Tompsett, I95 I), but infections of the gastro-intestinal tract and peptic ulcers, have also been blamed (Sirota, Gerber and Baehr, 1947).

\section{Early Diagnosis of Subacute Bacterial Endo- carditis}

In subacute bacterial endocarditis the diagnosis should not be deferred until there are such physical signs as clubbing of the fingers, splenomegaly, petechias, Osler's nodes and systemic embolism. The disease should be suspected from the symptoms. How vague and ill-defined these symptoms may be was well shown in the M.R.C. trials. The mode of onset was studied in a group of patients. Initial symptoms in about two-thirds of patients were those attributable to their having a fever; most commonly this was merely sweating. Only one in six had chills or shivering and rigors were rare. The illness began with malaise, tiredness, weakness and, perhaps, generalized aches and pains in 40 per cent. of cases. A small number ( 6 per cent.) noticed early loss of weight, and a few complained at first of headache and of nausea and vomiting. Others began their illness with more precise complaints, but even these tended to be dangerously misleading. Shortness of breath and slight swelling of the ankles was noticed in about 30 per cent. and joint pains in 17 per cent.; it is not certain whether this means that these patients had also a reactivation of acute rheumatism, but whatever the explanation these symptoms are deceptive. There was a systemic embolism at the onset in 20 per cent., but in only a quarter of these was the embolism in the brain, eye or some other place which should arouse suspicion of an underlying bacterial endocarditis. Most emboli caused sudden pain over such organs as the spleen and kidney, or in the back or loin muscle mass, and it is easy to miss the significance of these symptoms.

Just as the first symptoms of bacterial endocarditis are vague and colourless so often are the earliest physical signs. Probably the best insight into the earliest signs of the disease was provided by patients who were observed while relapsing after unsuccessful penicillin treatment; in most cases all that could be found was a temperature rising above normal in the evenings, a raised erythrocyte sedimentation rate and a positive blood culture. How long it takes for the classical signs to develop is well illustrated by these findings in one centre (Matthew and Gilchrist, 1948-49). There the average duration of symptoms before admission to hospital was three months, yet the spleen was palpable in only 48 per cent., the fingers were clubbed in 48 per cent., haematuria was found in 40 per cent., Osler's nodes in 35 per cent., and petechiae in 35 per cent. Seabury (1947) has also shown how often these and other traditional signs of the disease were not to be seen. It clearly follows that to postpone the diagnosis while waiting for clubbing, splenomegaly, petechiae and other signs that may never come is merely to allow vegetations to destroy valves beyond hope of recovery and to increase the chance of cerebral embolism or of the bursting of a mycotic aneurysm.

To sum up, any patient with a valvular lesion or congenital heart defect who complains of sweats and lassitude must be suspected of having subacute bacterial endocarditis. A raised evening temperature and a raised erythrocyte sedimentation rate increase the suspicion and warrant blood cultures.

\section{Diagnostic Significance of Blood Cultures}

A positive culture in a cardiac patient does not prove that bacterial endocarditis has developed. From time to time blood cultures are positive in people with dental sepsis, and even the most careful technique does not prevent occasional contamination of blood cultures. For these reasons it is advisable to obtain a second positive culture before accepting the evidence, particularly when the organism is a common contaminant such as Staphylococcus albus.

A negative blood culture, on the other hand, does not exclude the presence of bacterial endocarditis. Blood cultures may be reported as negative because the laboratory investigation has been incomplete; the important omissions that cause this mistake are failure to make an anaerobic culture (in this way such pathogens as microaerophilic streptococci may be missed), and failure to incubate cultures for three weeks (growth may not be visible in a shorter time). Even when these 
refinements are practised, blood cultures are positive on the first attempt in only about 80 per cent of cases, and two, three and even four attempts should be made before abandoning the diagnosis or labelling the case ' abacteraemic.'

In this country blood cultures are usually taken on succeeding days, and there is a fashion, for which there is little experimental support, to take cultures when there is a rising temperature. In America blood cultures are taken at hourly intervals during one day; there is much to commend this technique in urgent cases where empirical treatment must be begun before full bacteriological findings are complete (Hunter, 195I).

When cultures of venous blood are negative some authorities advocate arterial cultures and even cultures of sternal marrow. These modifications, particularly the latter, are of doubtful value, for the increased risk of contamination must make any positive findings of less diagnostic importance.

\section{Patients with Negative Blood Cultures}

In some patients who, on clinical grounds, seem to have bacterial endocarditis, blood cultures are persistently negative. There are three main reasons for this:

I. When organisms are present in the peripheral blood but are not grown on culture the reason is commonly faulty technique. These errors have been discussed above.

2. Although organisms are present in the vegetations they are scanty or absent in the peripheral blood; this group has been well described by Keefer (1937). There are three suggested causes of this anomaly: (a) In some cases organisms are confined to the depths of the vegetation. (b) In some cases there is a high titre of antibodies in the patient's blood and circulating organisms are soon killed. (c) When infection is confined to the right side of the heart the systemic blood may be sterile, and this has been attributed to trapping of organisms in the pulmonary capillaries (Barker, 1949).

(3) Organisms are not present in the vegetations. Reports on these cases are provocative and puzzling for they challenge the accepted ideas about the aetiology of bacterial endocarditis. Libman and Friedberg described a clinical picture which they called ' the bacteria-free stage' which may evolve from bacterial endocarditis when infection is eliminated. This state is distinguished from the after-effects of adequate penicillin therapy by persistent anaemia, splenomegaly, pigmentation or uraemia (Friedberg, 1949). Trias de Bes (1947) has reported a rather similar group of ' abacteraemic 'cases in Spain; his patients were mostly men who were undernourished and gave a history of previous rheumatic infection. Although orgat isms were sometimes found in the vegetations, implies that bacterial infection is neither an i\& variable nor a dominant feature of the disease. Response to antibiotics was disappointing, whiç supports his idea that bacterial infection was nơt the only form of activity present. Although this interpretation of abacteraemic cases may accepted with some reserve it is well to recall the in Libman-Sach's disease the nature of the' vegetations is not known, and that in a few of these there is secondary bacterial infection of these vegetations.

Most of the cases with negative blood cultures that are seen in this country and America (Loewe and Eiber, 1947) appear to be those with bactefo in the vegetations and treatment with antibiotics is worthwhile.

\section{Significance of Infecting Organism}

When the infecting organism is known, seare can be made in likely places for a primary focus of infection. Illustrations of this are given above; for example, the finding of an enterococcus should direct the search to the alimentary or urinary tracts. The finding of haemolytic streptococci of groups B, C or G strongly suggests ght the infection has sprung from the genital falet after an abortion (Ramsay and Gillespie, r. Dolphin and Cruickshank, I945).

Clinical features peculiar to different organisro are already well established (Perry, 1936). Ho ever, it is surprising that even with chemotherafy there is still a real danger of meningitis in pnewmococcal endocarditis (Anderson and Keefer, I948). An interesting feature of endocarditis dwe to streptococci of groups B, C and G is the high risk of massive peripheral embolism. Vegetations are often large and friable, and this has been attributed to the fact that, unlike group A streptococci, no fibrinolysin is made by these organism.

\section{Significance of Sensitivity Tests}

The most important reason for obtaini@g positive blood cultures is that the sensitivity of the organism to antibiotics can be measured. But make use of these laboratory measurements it necessary to understand their limitations. There are three current fallacies:

I. The first fallacy is that the choice of ante biotic for treatment is decided by the results of various sensitivity tests. This misconception arese in the following way. The ordinary laboratowy tests of sensitivity depend upon whether or not the growth of organism is prevented, that is to say, the presence or absence of bacteriostasis: on the other hand, there is now little doubt that the best results in bacterial endocarditis are obtained with 
drugs that are actually bactericidat. Because penicillin is bactericidal as well as bacteriostatic there was a good correlation between in vitro sensitivity tests and the therapeutic results; the same is true with streptomycin. But the more recent antibiotics such as chloromycetin and aureomycin, like the sulphonamides, are mainly bacteriostatic, and results of treatment with them have been almost as disappointing as were those with sulphonamides: an infecting organism may show great sensitivity in vitro but bacteraemia either persists during treatment or returns soon after. From first reports, terramycin seems to have the same failing (Friedberg, 1952).

2. The second fallacy is that if on the ordinary tests an organism is sensitive to two antibiotics it will necessarily be of benefit to give the patient both together. The bactericidal effect of mixed antibiotics is only revealed by performing viable counts. By this technique it has been clearly shown that the bactericidal action of penicillin on most organisms is enhanced by adding streptomycin. On the other hand, the newer antibiotics, which are bacteriostatic, depress the bactericidal action of penicillin. (Jawetz, Gunnison and Coleman, 1950; Cates, Christie and Garrod, I95I; Jawetz and Gunnison, 1950; Gunnison, Coleman and Jawetz, r950 a and b.)

Clinical results are in keeping with these recent findings; not only in endocarditis (see below) but in pneumococcal meningitis the combination of aureomycin and penicillin gives a higher death rate than the same dosage of penicillin alone (Lepper and Dowling, 195I). Likewise in mice the protective power of penicillin against streptococcus haemolyticus is appreciably less when chloromycetin is given as well (Jawetz and Speck, 1950), and aureomycin apparently behaves in the same way (Dowling, Lepper and Roth, 195I).

3. The third fallacy is that an infection will be eliminated if penicillin in plasma is maintained at a level which is effective in vitro (i.e. in the sensitivity tests). Penicillin-sensitive organisms are quickly killed in vitro by a level of penicillin a little more than that needed to stop their growth (Massell, Meyeserian and Jones, I946) but the best results in endocarditis are achieved when plasma penicillin levels are a hundred times the in ritro figure (Seabury, I947). 'This disparity has partly been explained by some recent work by Hunter (195I); he has shown that organisms growing in clots of fibrin are less susceptible to antibiotics than they are when growing in a fluid medium.

\section{Choice of Treatment}

To determine how best to treat bacterial endocarditis several hundreds of patients have been carefully studied in well-planned clinical trials. ڤ So today the right treatment in most cases is that $\frac{3}{0}$ which has already been found to give the best $\stackrel{\mathbb{Q}}{\circ}$ results in similar cases. Only rarely is it justifiable $\stackrel{c}{\hookrightarrow}$ to resort to untried or experimental therapeutics, $\overrightarrow{\vec{D}}$ and these difficult problems are best referred to $\frac{7}{0}$ some centre which has had special experience. - $\frac{\mathrm{C}}{0}$

There is no doubt that whenever an infecting $\frac{\bar{c}}{\bar{c}}$ organism is sensitive to penicillin, then penicillin is the drug to use. In about 85 per cent. of cases of subacute bacterial endocarditis the sensitivity of क tne organism is close to that of the Oxford $H . \vec{O}$ staphylococcus (growth being inhibited by $0.02 \overrightarrow{-}$ units per $\mathrm{ml}$.); in these cases the daily dose of $\bar{\sigma}$ penicillin should be two million units (Christie, $\frac{D}{\circ}$ 1949), and this should be given by three-hourly 3 . injection. With organisms that are four or more times as resistant as the Oxford $H$. staphylococcus $\underset{\omega}{\infty}$ there is no certainty that this dose of penicillin $N_{0}$ will eliminate the infection; it is therefore advis- $\omega$

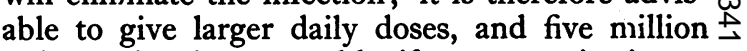
units a day is reasonable if the organism's re- 우 sistance is between four and ten times that of the standard organism.

-In about 3 per cent. of cases the infecting or- $\frac{\subsetneq}{\Phi}$ ganism is more than ten times as resistant as the $\vec{\theta}$ Oxford H. staphylococcus. These organisms a o o usually enterococci or penicillin-resistant strains $N$ of streptococci of the viridans group and the growth may be inhibited by anything between, say, 0.5 and 5 or 10 units of penicillin per $\mathrm{ml}$. As these infections are relatively uncommon the best method of treatment cannot be decided by $\stackrel{\square}{\square}$ adequate clinical trials and can only be deduced $\overrightarrow{\overrightarrow{0}}$ from reports on small groups or single cases. 3 From these it seems that treatment with penicillin alone may succeed in eliminating infection, but massive doses are necessary and even then these $\bar{\partial}$ may be successful only if penicillin excretion is delayed by some substance such as caronamide or $\overline{3}$ benamid (Hunter, 1946; Loewe, Rosenblatt and Alture-Werber, 1946; Grossman, Feldman, Katz $ᄋ$ and Brams, 1947; Hagedorn and Scheifley, 1948; Leaman, Wikingsson, Webster and Shaw, I949; 옥 Stuart-Harris, Colquhoun and Brown, 1949; $>$ Levinson, Griffith and Pearson, 1951). In one recent account a Streptococcus viridans needed N between 10 and 20 units of penicillin per $\mathrm{ml}$. to inhibit growth and this infection was eventually $\mathcal{N}$ eliminated by an average daily dose of 86 million $\underset{\omega}{\omega}$ units (Whipple, I95 I). But infection may persist even with enormous doses (Zeller et al., 1948; Cates, r949), so in all these penicillin-resistant infections it is advisable to consider using streptomycin.

Streptomycin alone may sometimes succeed in $\frac{\overrightarrow{0}}{\mathbb{D}}$ penicillin-resistant infections (Priest and McGee, $\frac{O}{\stackrel{O}{O}}$ 1946; Paul, Bland and White, 1947; Massell, $\stackrel{\unrhd}{\circ}$ 
Zeller, Dow and Harting, I948; Pearsall, Pillow and Wood, 1948; Naegele, r 949), but in only four of the 18 cases analyzed by Hunter could streptomycin certainly be said to have cured the patient. The resistance of the infecting organisms to streptomycin is of great importance, and of the 18 cases reviewed by Hunter (1947) ' treatment was not successful in any case in which the organism required more than $8 \mu \mathrm{g}$. per $\mathrm{ml}$. for in vitro inhibition of growth,' though Naegele reported one success with an organism that needed I $6 \mu \mathrm{g}$. per ml. to inhibit its growth. However, both newer laboratory techniques and clinical reports indicate that better results may be expected from a combined course of streptomycin ( 2 or $4 \mathrm{~g}$. daily) and penicillin ( 10 or 20 million units daily) (Hunter, 1946, 1947, I951 ; Robbins and Tompsett, I949, I951; Cates, Christie and Garrod, 195I). These doses of streptomycin are likely to cause vestibular damage, but the price is cheap if infection is eliminated.

Staphylococcal endocarditis threatens to become the most difficult form to treat. One reason for this is that endocarditis due to coagulasepositive staphylococci is an acute infection, often overwhelming a patient in a matter of a week or so. Another reason is that nowadays many strains of both coagulase-positive and coagulase-negative staphylococci causing endocarditis show considerable resistance to penicillin before treatment is begun. Thirdly, any staphylococcal sepsis, even when due to penicillin sensitive strains, responds less well to penicillin than infections due to other penicillin sensitive organisms (Anderson and Keefer, 1948). Therefore if the organism is found to be fully sensitive in vitro it is advisable to give at least two million units of penicillin daily. Penicillin-resistant staphylococci arè sometimes quite sensitive to streptomycin (growth being inhibited by under $8 \mu \mathrm{g}$. per ml.); it is then worth giving this drug (Wilhelm et al., 1947). In those staphylococcal infections with an organism resistant to penicillin but sensitive to about I $\mu \mathrm{g}$. of aureomycin it is justifiable to try a course of aureomycin (Levinson et al., loc. cit.).

In about 2 per cent. of published cases infection is due to the influenza bacillus (Thayer, 193I; Perry, 1936). Most of these infections are really due to Haemophilus para-influenzae (Miles and Gray, 1938), but $H$. influenzae itself has caused some infections (Aubert, 1950; Martin and Spink, 1947). These infections may be very difficult to eradicate for they are often insensitive to penicillin and develop resistance to streptomycin. It is therefore worth remembering that before the days of penicillin Schein and Baehr (1948) cured two of three cases with sulphonamide alone, and more recently the combined use of penicillin and sulphonamide has cured two other $\cong$ patients (Aubert, 1950; Luttgens, 1949); in these 3 two cases the organism was penicillin-resistant. $\stackrel{\mathbb{Q}}{\complement}$ This type of bacterial endocarditis seems to be the $C$ only one in which sulphonamides may be worth $\overrightarrow{\vec{D}}$ while. It has recently been suggested that in these infections aureomycin may be preferable to $\frac{0}{\circ}$ streptomycin (Friedberg, 1952), but there is as $\frac{\bar{C}}{\bar{c}}$. yet little evidence to support this view. It has also $\frac{\vec{\Phi}}{\vec{D}}$ been suggested that polymyxin $B$ may be of value $\frac{\Omega}{0}$ (Hunter. I95 I).

The list of rare organisms in bacterial endo- $\overrightarrow{0}$ carditis continues to grow and Jones (1950) has collected 204 references of subacute infections $\vec{\omega}$ that were not streptococcal. There is little point $\frac{\sigma}{D}$ in further discussion of these here for the choice $\frac{0}{3}$ of treatment rests upon the principles given above. Nevertheless there have been two reports $\stackrel{0}{0}$ that curious mixtures of antibiotics which were $\underset{N}{\omega}$ potent in vitro were also successful clinically. In $\underset{\omega}{\circ}$ one, a mixture of terramycin and streptomycin $\triangleq$ was given in an infection with Staphylococcus $\overrightarrow{0}$ albus (Jawetz, Gunnison and Speck, 1951); in the other bacitracin and penicillin were given in $\subsetneq$ an infection due to a diphtheroid (Wallach and $\frac{\widehat{D}}{5}$ Pomerantz, I95I).

\section{Treatment of bacteriologically negative Cases}

In those patients who seem to have bacteria endocarditis on clinical grounds although bloo cultures are repeatedly negative it is justifiable to give empirical treatment. Clinical signs of in- ֶ fection often respond to penicillin, although it $\stackrel{\square}{\circledR}$ may be found necessary to give large doses (Loewe $\overrightarrow{\vec{A}}$ and Eiber, 1947). For this reason it is advisable to $\frac{3}{3}$ begin with at least 5 million units daily. Should penicillin fail to cause clinical response then? streptomycin is worth trying (Wilcox, 1950). Un- $-\frac{1}{0}$ fortunately in these abacteraemic patients there is 3 . a high incidence of heart failure before treatmenti is begun, so even if the infection may respond well? to therapy the final prognosis is often very bad.

\section{Penicillin Administration}

Penicillin was originally given by intravenous or intramuscular infusion. These routes were thought to have the theoretical advantage of keep-ñ ing the plasma level constant. The usual method? used to day is intermittent, intramuscular in- $N$ jection; it is simpler, and there is less risk of muscle abscess and none of phlebitis. Moreover, ito is now thought that penicillin may penetrate intoo vegetations more readily when plasma levels arē high shortly after each injection. Procaine peni-? cillin in oil is unsatisfactory when given in big doses, and watery suspensions of this preparation have not yet been shown to be effective in any proper clinical trial. Therefore crystalline peni $\frac{\mathbb{Q}}{\Omega}$ 
cillin given by intramuscular injection every three hours day and night is still the safest practice.

\section{Length of Treatment}

Clinical trials in this country have proved beyond all doubt that it is necessary to continue treatment for at least one month (Christie, 1948); and even enormous doses of penicillin are of very little value if treatment is given for only ten days (King, Schneierson, Sussman, Janowitz and Stollerman, 1949). The principle should be to give a course long enough to be safe, not the shortest known to have succeeded; and it is now the usual practice to give six weeks' treatment.

\section{Effects of Treatment}

When treatment is successful a patient begins to feel much better within a few days; his appetite returns and he begins to put on flesh. The temperature usually falls to normal in the course of a week or less, and patients often remain apyrexial for the rest of their treatment. When the cruder preparations of penicillin were used six years ago it was common to see some fever throughout the course of treatment; but nowadays persistent fever should be taken as a sign of persistent infection. The E.S.R. likewise used to remain high throughout the course, especially when there was reaction around the sites of injection; but, again, with the purer penicillin used to day it is common for the E.S.R. to begin to fall soon after treatment starts. In successful cases the E.S.R., if still above normal by the end of treatment, falls to normal within a week. If it remains raised or falls only to rise again, one must be suspicious that infection is returning.

Anaemia is repaired surprisingly slowly, and the blood count may not reach normal limits until three months (Jones, Herring, Langley and Oleesky, 1947). The urine often contains albumin, red cells and casts for several weeks after the end of treatment, but it is usually normal within six months.

It is now well known that for several weeks after infection has apparently been eradicated there is a risk of an arterial embolism (Tumulty and Harvey, 1948; Cates and Christie, 195I). Therefore the presence of anaemia, microscopic haematuria and peripheral emboli does not necessarily mean that treatment has failed to eliminate infection.

\section{Unsuccessful Treatment}

Infection may be uncontrolled by treatment or may relapse after treatment has-been stopped. (a) In uncontrolled infections the clinical response is often transient or absent, and positive blood cultures persist throughout the course. Some- times the clinical response seems complete; but blood cultures grow single or scanty colonies; this finding after the first day or so of treatment almost invariably means that infection has not been sup- $c$ pressed and will not be eliminated by that method of treatment. (b) In cases that relapse, both $\stackrel{\text { ? }}{+}$ clinical and bacteriological responses are satis- $\bar{c}$ factory during treatment. But within a week or $\overline{\mathrm{F}}$ so of stopping treatment there is a gradual rise of $\frac{\vec{m}}{\vec{\omega}}$ temperature in the evenings, the E.S.R. is above $\mathbb{\mathbb { D }}$ normal and blood cultures become positive. in About $9 \circ$ per cent. of patients who relapse do so within a month of stopping treatment.

\section{Delayed Relapses}

In about 2 per cent. of cases each year infection occurs again, although many of these cases are reinfections it is possible that some are, in fact, true relapses. This speculation is supported by the $\dot{c}$ finding of apparently viable organisms buried deep . in the scarred vegetations of 33 per cent. of $\underset{\perp}{\omega}$ patients dying with their infection apparently controlled. However, there is no proof that a few organisms trapped in the depth of fibrosed vegetations are not compatible with healed bacterial endocarditis.

\section{Death in 'Cured' Patients}

With proper treatment infection can apparent be controlled in nearly every case of bacteriat endocarditis, but unfortunately many patients still die during treatment or soon after. In the M.R.C. series, infection was apparently controlled in 363 cases; of these 13 per cent. died during treatment, Io per cent. within a month after treatment and another 12 per cent. by the end of the sixth month-leaving 65 per cent. alive. From then until the end of the fourth year the death rate of the survivors was only 4 per cent. per annum.

In these 'cured' patients death was due to heart failure in $5^{8}$ per cent., and of those dying after the sixth month heart failure was the cause in 79 per cent. Extensive destruction of the valves and chordae tendineae was often found, but it is perhaps surprising that coronary embolism was seen in as many as 13 per cent. of these postmortems. Less common causes of death in convalescence were arterial embolism and cerebral o haemorrhage. Death was due to uraemia only if $N$ there had been severe renal damage such as $\underset{\omega}{N}$ glomerulonephritis before treatment began.

\section{Prognosis When Infection is Apparently Con- trolled}

Although 35 per cent. of patients with apparently controlled infections die within six months of treatment, the prognosis for different patients varies widely; in some patients prognosis is 
almost hopeless before treatment begins, in others the chance of surviving six months is over 80 per cent.

\section{Age}

The older the patient the worse is the prognosis. The proportion surviving six months after treatment is 70 per cent. of patients under 40,60 per cent. of those between 40 and 50 and 46 per cent. of those over 50 years old.

\section{Sex}

Females have a slightly better prognosis than males, this is partly because women are infected at a younger age than are men and they more often have mitral disease alone which carries a better prognosis than other acquired lesions.

\section{Heart Failure}

The presence of heart failure before treatment begins is a grave prognostic sign. Thus in patients whose infection is apparently unsuccessfully controlled by penicillin the presence of some heart failure reduces to 21 per cent. the chance of surviving six months after treatment, while of those with no heart failure 77 per cent. survive after this time. It is likewise a bad sign for heart failure to appear during treatment, for in those cases only 2 I per cent. survive compared with an 82 per cent. survival in patients who do not develop heart failure during treatment.

\section{Underlying Lesion}

Congenital heart lesions have a better prognosis than acquired-the survival rate at six months being 87 per cent. in congenital and 62 per cent. in acquired lesions.

In acquired lesions the prognosis is better for disease of the mitral valve alone than for aortic disease or disease of both valves, the survival rate at six months for mitral valve disease being $7 \mathrm{I}$ per cent., while for disease of the aortic valve alone and for disease of both valves the survival rates are both 53 per cent.

\section{State of Nutrition}

A well-nourished patient stands a far better chance of survival than one who is badly nourished or emaciated. This is independent of coexisting heart failure, for of patients without heart failure the badly nourished have a worse prognosis than those in a good state.

\section{Duration of Infection}

If treatment is begun within ten weeks of the onset of symptoms (and infection is thereby apparently controlled) the survival rate at six months is 77 per cent.; if the interval is ro to 20 weeks the rate is 67 per cent., and over 20 weeks the rate is $5^{\circ}$ per cent. This seems to be due to $\frac{a}{z}$ the presence of heart failure in those patients $\frac{0}{8}$ whose treatment is begun late.

\section{Prophylaxis}

Acute bacterial endocarditis is now largely pre-음 vented by the widespread use of antibiotics in $\frac{\overline{\bar{N}}}{\bar{n}}$ many infections.

In patients with congenital or rheumatic heart $\stackrel{\mathbb{Q}}{\varrho}$ disease the main danger of developing subacute bacterial endocarditis lies in untreated dental $\vec{\circ}$

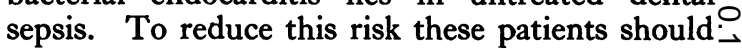
receive dental attention every six months or so, $\vec{\omega}$ and any questionable tooth should be X-rayed because some apical abscesses can be detected in 0 을 no other way. Infected gums are not sterilized by giving short courses of penicillin, and even a full ${ }_{\infty}$ course for bacterial endocarditis may fail to kill $\omega$ penicillin sensitive organisms buried in the depths? of an apical abscess. This means that to eliminate $\omega$ dental sepsis various surgical procedures such as $\vec{\circ}$ scaling and extraction must be faced, though with proper prophylactic use of antibiotics the risk is $\vec{c}$ small.

The bacteraemia caused by dental extraction ${ }^{\overparen{ }}$ is not always prevented by sulphonamides, pend- $\overrightarrow{0}$ cillin (Glasser et al., 1948) or aureomycin (Rot in et al., 1950). Penicillin, however, can exert bactericidal action on those organisms which ame implanted on a heart valve. For this reason penicillin is the drug usually used. There is no@ point in beginning this prophylactic penicillin for $\frac{\text { o }}{2}$ more than perhaps half an hour before dental ex- $\stackrel{\varrho}{\Rightarrow}$ traction; not only is bacteraemia not prevented by longer therapy, but there is an added risk $\vec{J}$ because the normal penicillin-sensitive flora of the mouth is rapidly replaced by penicillin-resistant organisms. A few cases of bacterial endocarditis 3 have been reported after prophylactic penicillin but in most of these the dosage was small as judged 3 . by present standards (Hunter, 195 I). The present recommended dosage of 250,000 units every three hours for two or three days is the ideal, but thiso means admission to hospital, which is often impracticable. More knowledge is needed of theo protective action of more convenient preparations such as mixtures of soluble and procaine penicillin.

Bacteraemia may follow almost any surgical 0 manoeuvre ranging from tonsillectomy, abdominal operations and incision of boils to such minor interferences as passing catheters and gynaecological instruments and passive movements of $\frac{\bar{\Phi}}{\bar{D}}$ joints (Glasser et al., 1948; King, 1948); abortion $\stackrel{?}{?}$ and normal delivery are likewise dangerous. The 0 choice of antibiotic for prophylaxis depends on the organism likely to cause bacteraemia. In many cases penicillin is obviously suitable, when it is $\frac{\vec{Q}}{Q}$ 
not, for example a prostatectomy in the presence of $B$. coli. urinary infection, it is worth investigating the antibiotic sensitivity of the infecting organism.
In the wider field, prevention of bacterial endocarditis depends on preventing congenital and rheumatic heart disease, but consideration of this problem is outside the scope of this review.

\section{BIBLIOGRAPHY}

ANDERSON, D. G., and KEEFER, C. S. (1948), 'The Therapeutic Value of Penicillin. A Study of 10,000 Cases,' $A n n$ Arbor, Michigan.

AUBERT, A. (1950), Amer. Heart F., 39, I4I.

BARKER, P. S. (1949), Amer. Heart $\mathcal{F}$., 37, 1054.

CUTLER, S. S., and WOLF, J. (1946), Ann. intern. Med., 25, 972.

CATES, J. E. (1949), Clin. Sci., 8, 53.

CATES, J. E., and CHRISTIE, R. V. (195I), Quart. F. Med. (N.S.), 20, 93 .

CATES, J. E., CHRISTIE, R. V., and GARROD, L. P. (195I), Brit. med. $\mathcal{Y}$., i, 653 .

CHRISTIE, R. V. (1948), Ibid., i, I.

CHRISTIE, R. V. (1949), Ibid., ii, 950.

DOLPHIN, A., and CRUICKSHANK, R. (1945), Ibid., i, 897.

DOWLING, H. F., LEPPER, M. H., and ROTH, E. (I'55), unpublished data quoted in Arch. intern. Med., 88, 489.

FELDMAN, L., and TRACE, I. M. (1938), Ann. intern. Med., II, 2124.

FIRESTONE, G. M. (1946), Amer. F. med. Sci., $211,556$.

FRIEDBERG, C. K. (1949) 'Diseases of the Heart,' W. B. Saunders Coy., London.

FREIDBERG, C. K. (1952), F. Amer. med. Ass., 148, 98.

GLASER, R. J., DANKNER, A., MATHES, S. B., and HARFORD, C. G. (1948), Amer. $\mathscr{\exists}$. Med., 4, 55.

GROSSMAN, M., FELDMAN, D., KATZ, L. N., and BRAMS, W. (1947), Amer. Heart F., 34, 4.

GUNNISON, J. B., COLEMAN, V. R., and JAWETZ, E. (I95०a), Proc. Soc. exp. Biol., N.Y., 75, 549.

GUNNISON, J. B., COLEMAN, V. R., and JAWETZ, E. (195०b), F. Lab. clin. Med., 36, 900 .

HAGEDORN, A. B., SCHIEFLEY, C. H. (1948), Proc. Mayo Clin., 23, 14

HARVEY, J. C., MIRICK, G. S., and SCHAUB, I. G. (1949), F. clin. Invest., 28, 987.

HUNTER, T. H. (1946), Amer. F. Med., r, 83.

HUNTER, T. H. (1947), Ibid., 2, 436.

HUNTER, T. H. (195I), Amer. Heart F., 42, 472.

HURST, W. W., GLEASON, A. L., and SCHEMM, F. R. (1949), Northw. Med., Seattle, 48, 763.

JAWETZ, E., and GUNNISON, J. B. (1950), f. Lab. clin. Med., $35,488$.

JAWETZ, E., GUNNISON, J. B., and COLEMAN, V. R. (1950), Science, 111, 254.

JAWETZ, E., GUNNISON, J. B., and SPECK, R. S. (1951), New Engl. F. Med., 245, 966.

JAWETZ, E., and SPECK, R. S. (1950), Proc. Soc. exp. Biol., N.Y., 74,93 .

JONES, A. M. HERRING, R., LANGLEY, F. A., and OLEESKY, S. (1947), Brit. Heart $\mathcal{F}$., 9, 38

JONES, M. (1950), Amer. Heart F., 40, 106.

KEEFER, C. S. (1937), Ann. intern. Med., I1, 714.

KING, E. S. (1948), Amer. Practit., Phila., 2, 29 I.

KING, F. H., SCHNEIERSON, S. S., SUSSMAN, M. L. JANOWITZ, H. D., and STOLLERMAN, G. H. (1949), $\mathcal{f}$. Mt. Sinai Hosp., 16, 35.

LEAMAN, W. G., WIKINGSSON, M. B., WEBSTER, M. B., and SHAW, C. C. (1949), Ann. intern. Med., 30, 646.

LEPPER, M. H., and DOWLING, H. F. (195I), Arch. intern. Med., 88, 489 .

LEVINSON, D. C., GRIFFITH, G. C., and PEARSON, H. E. (1950), Circulation, 2, 668
LEWIS, T., and GRANT, R. T. (1923), Heart, ro, 21.

LOEWE, L., and EIBER, H. B. (1947), Amer. Heart F., 34, 349. LOEWE, L, ROSENBLATT, P., and ALTURE-WERBER, E. (1946), Ibid., 32, 327.

LUTTGENS, W. F. (1949), Arch. intern. Med., 83, 653.

LUXTON, R. W, and SMITH, G. S. (1943), Quart. 7. Med , ra $6 \mathrm{I}$.

MCDONALD, R. K. (1946), Amer. Heart f., 31, 308.

MACILWAINE, Y. (1947), F. Path. Bact., 69, 557.

MARTIN, W. B., and SPINK, W. W. (1947), Amer. F. med. Sci. 214, 139.

MASSELL, B. F., MEYESERIAN, M., and JONES, T. D. (1946), F. Bact., 52, 33 .

MASSELL, B. F., ZELLER, J. W., DOW, J. W., and HARTING, D. (1948), New. Engl. F. Med., 238, 464

MATTHEW, H., and GILCHRIST, A. R. (1948-49), Trans. Med.-Chir. Soc. Edinb., 128, 25.

MILES, A. A., and GRAY, J. (1938), F. Path. Bact., 47, 257.

NAEGELE, C. F. (1949), Ann. intern. Med., 30, 1049.

PAUL, O., BLAND, E. F., and WHITE, P. D. (1947), New Engl. F. Med., 237, 349 .

PEARSALL, H. R., PILLOW, R. P., and WOOD, J. E. (1948), Amer. Practit., Phila., 2, 497.

PERRY, C. B. (1936), 'Bacterial Endocarditis,' John Wright \& Sons, Ltd., Bristol.

PRIEST, W. S., and MCGEE, C. J. (1946), f. Amer. med. Ass., 132, 124.

RAMSAY, A. M. (1950), personal communication.

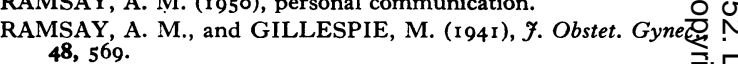

ROBBINS, W. C., and TOMPSETT, R. (1949), f. clin. Inves 28, 1043 .

ROBBINS, W. C., and TOMPSETT, R. (1951), Amer. F. Med., I0, 278.

ROTH, O. CAVALlaRO, A. L., PARROTT, R. H., and CELENTANO, R. (1950), Arch. intern. Med., 86, 498.

SEABURY, J. H. (1947), Ibid., 79, I.

SCHEIN, J., and BAEHR, G. (1948), Amer. F. Med., 4, 66.

SIROTA, J. H., GERBER, I. E., and BAEHR, G. (1947), f. Mt. Sinai Hosp., 14, 604.

STOJANOVIC, V., and SLAVKOVIC, J. (1948), Arch. Serbed Med., 46, 827.

STUART-HARRIS, C. H., COLQUHOUN, J., and BROWN, J. W. (1949), Lancet, i, 99 .

THAYER, W. S. (1931), Edinb. med. F., 38, 237.

TINSLEY, C. M. (1945), Arch. intern. Med., 75, 82.

TRIAS DE BES, L. (1947), 'Endocarditis agudas y subagudas, 3 Primera Ponencia, Barcelona.

TUMULTY, P. A., and HARVEY, A. M. (1948), Amer. F. Med., 4, 37.

WALLACH, R., and POMERANTZ, N. (1951), Arch. intern. Med., 88, 840 .

WHIPPLE, R. L. (195I), Amer. Heart f., 42, 414.

WILCOX, P. H. (1950), Lancet, ii, 288.

WILHELM, F., HIRSH, H. L., HUSSEY, H. H., and DOWLING, H. F. (1947), Ann. intern. Med., 26, 22 I.

ZELLER, W. W., HIRSH, H. L., DOWLING, H. F. ,HUSSEY, H. H., and ROBINSON, J. A. (1948), Med. Ann. Distr. N Columbia, 17, 21. 